\title{
The Relationship Between Work Intensification and Employee Learning in a Cognitive Appraisal Perspective
}

\author{
Tingli Yang*, Xiaoting Qu and Yuanyuan Lan
}

Beijing Jiaotong University, Beijing, China

${ }^{*}$ Corresponding author. Email: 18322441093@163.com

\begin{abstract}
Based on the cognitive interaction theory of stress, this paper explores the effects of work intensification on employee learning and examines the mediating role of cognitive appraisal. Finally, the study finds that work intensification can influence employee learning in the workplace through the fully mediating role of challenge appraisal. The results verify the potential value of work intensification to employee learning, supplement the research on work intensification, and provide a reference for talent incentive management in enterprises.
\end{abstract}

Keywords: Work intensification, Employee learning, Cognitive appraisal.

\section{INTRODUCTION}

On April 2019, a topic named "996 · ICU" was spread on the Internet in domestic procedural circles, which led to the discussion of work intensification. Work intensification refers to a process in which employees' efforts are constantly strengthened under the situation of high work pressure and high job demand [1]. With the fierce market competition and the rapid development of information technology, enterprises are facing more and more difficulties and challenges so that they choose work intensification to improve the competition power. This means employees need work more efficiently and complete more tasks in limited time, which lead to work pressure and bad mood. In this process, how work intensification can promote employee learning in the workplace is playing an increasingly important role. Therefore, what is the specific impact mechanism of work intensification? How to avoid the adverse effects of job intensification on employees? This problem has drawn more and more attentions of organizations and scholars.

\section{LITERATURE REVIEW}

\subsection{Work Intensification}

At present, there are mainly two concepts of work intensification. One is that work intensification is basically equivalent to the increase of work intensity, which has the characteristics of faster work speed, more work tasks and less leisure time during work $[2,3]$. The other view is the extension of the former view, work intensification refers to the increase of work demand or efforts required of employees during statutory working time, and the increase of occupation of employees' private life by work [4]. Due to the common phenomenon of work overtime in China, this study selects the second view.

In order to clearly explain the concept of work intensification, this paper distinguishes work intensification from work intensity and overload. Work intensity usually refers to the degree of physical and psychological loss caused by work in unit time, which can be regarded as a static concept [5], while work intensification is a dynamic concept, which reflects the dynamic change of work intensity. Overload usually refers to the adverse consequences such as physical and mental fatigue and "overwork death" caused by continuous high-intensity work [6]. It focuses on the irreversible harm of excessive labor, while work intensification emphasizes the dynamic increase of work intensity and working hours, and its harmfulness depends on the degree and duration of intensification [4]. 


\subsection{Employee Learning}

Employee learning refers to the behaviors that employees can actively acquire new knowledge and skills, and improve their own ability in the workplace[7]. Due to the dynamic and complex environment, organizations need to constantly improve their learning ability to obtain sustainable competitive advantage. As the smallest cell of organizational learning, employees are the basic individuals of organizational learning, and they play a very important role in organizational development.

Employee learning in the workplace mainly has four characteristics: informal, situational, empirical and interactive [8]. In detail, under the specific working environment and task, the staff continuously accumulates experience through working practice and interacting with colleagues. Studies have shown that there are many factors including organizational factors and personal factors affect employee learning in the workplace. Specifically, the psychological capital of employees and leaders [9], the sense of psychological empowerment and psychological security of employees [10] all have an impact on employee learning. So, will work intensification have an impact on employee learning?

\subsection{Work Intensification and Employee Learning}

Some studies have found that employee learning is easily affected by the surrounding environment and atmosphere [11]. Organizational factors including providing learning opportunities plays an important role in promoting employee learning [12]. If employees regard work intensification as a learning opportunity to improve themselves and can actively increase knowledge and skills by completing various tasks, it will promote employee learning. On the contrary, if work intensification is considered by employees to occupy learning time and reduce learning opportunities, it is likely that work intensification will hinder employee learning in the workplace.

In addition, according to the cognitive interaction theory of stress, people will evaluate the stressors around them. There is often a reciprocal relationship between work pressure and employee learning, and the sense of gap caused by pressure will stimulate their own learning $[13,14]$ when employees make positive cognitive appraisal. When employees make negative cognitive appraisal, it will hinder learning and reduce self-efficacy. Since work intensification means more work tasks, more difficulties and challenges [3], this study believes that work intensification can be used as a source of stress to promote or hinder employee learning.

\subsection{The Mediating Role of Cognitive Appraisal}

People usually evaluate various things in the situation to judge the importance of these things to their own happiness. This psychological process is called cognitive appraisal [15]. Lazarus believes that cognitive appraisal process has two basic forms: primary appraisal and secondary appraisal. Primary appraisal refers to the process in which individuals evaluate the influence of stimulus on themselves, and secondary appraisal is the process of evaluating whether they can effectively respond to stimuli $[15,16]$. In the face of specific events, cognitive appraisal can be divided into two categories, namely challenge appraisal and hindrance appraisal [17]. If an employee thinks that the potential return or benefit brought by an event will be greater than the resources he has lost, he will often evaluate the event as a "challenge"; on the contrary, if the employee thinks that the potential benefit of the event will be less than the resources he has lost, or even hinder the realization of his goals, he will often evaluate the event as a "hindrance" [18].

Previous studies have shown that the influence of stressors on employees' behaviour is not only related to stress itself, but also to mediating factors such as cognitive appraisal [15]. At the same time, because work intensification means more urgent and more work demand, employees need to work harder and undertake more work pressure [19], which will inevitably affect the work attitude and behaviour of employees [20, 21]. Therefore, this paper believes that work intensification as a source of stress will affect employees' cognitive appraisal, and through cognitive appraisal will affect employees' work attitude and behaviour. This view has been preliminarily confirmed in the study of PA $\breve{s}$ kvan et al. [22], which believes that job intensification will affect employees' emotional exhaustion and job satisfaction through cognitive appraisal. In addition, cognitive appraisal is closely related to individual emotional response, physiological activities, work attitude and behaviour. The stressors considered as challenge by employees can stimulate their intrinsic motivation and promote their work commitment and innovation performance [18], which also helps employees learn and shape with a positive attitude [23]. When employees make a hindrance appraisal, it will cause employees emotional exhaustion and weakened creativity, which may have an adverse effect on employee learning. In summary, this study believes that cognitive appraisal is an important mediating variable between work intensification and employee learning. Based on this, this paper proposes the following hypotheses:

H1 Challenge appraisal mediates the relationship between work intensification and employee learning, that is, work intensification can promote employee learning through employee's challenge appraisal. 
H2 Hindrance appraisal mediates the relationship between work intensification and employee learning, that is, work intensification will hinder employee learning through employee's hindrance appraisal.

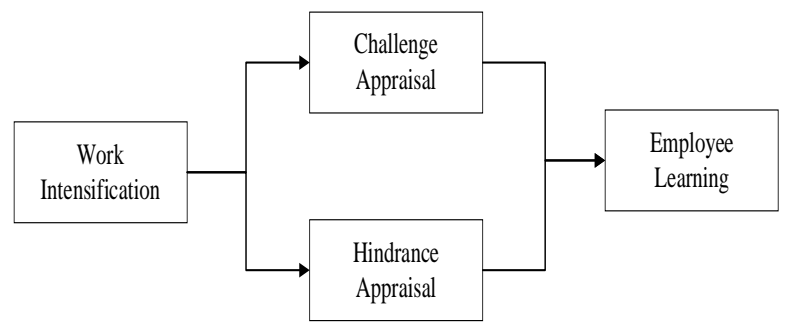

Figure 1 Research model

\section{METHODS}

\subsection{Data Collection}

Data were collected by an online questionnaire survey. The research samples are employees from different industries and enterprises, involving many fields such as service, construction and Internet. In order to ensure the quality of the data, the anonymity and voluntariness of the questionnaire were emphasized to the participants during the collection, and they were reminded to fill in the questionnaire carefully. In the end, a total of 251 questionnaires were collected. A total of 251 questionnaires were collected, and 220 questionnaires were finally valid, with an effective recovery rate of $87.6 \%$.

\subsection{Participants}

The preliminary statistics of the participants are as follows. In terms of gender, male accounted for $43.2 \%$, female accounted for $56.8 \%$; in terms of age, the proportion of 20 years old and below was $1.36 \%, 21-30$ years old accounted for $37.27 \%, 31-40$ years old accounted for $20.45 \%, 41-50$ years old accounted for $29.09 \%$, 51-60 years old accounted for $10.00 \%, 61$ years old and above accounted for $1.82 \%$; in terms of education, senior high school and below accounted for $19.55 \%$, technical secondary school and college accounted for $19.55 \%$, and the proportion of university was $49.55 \%$, and master's degree and above was $11.36 \%$; in terms of working years, $40.00 \%$ were under 5 years, $22.27 \%$ were $6-10$ years, and $15.91 \%$ were 11 15 years, $15.91 \%$ were $16-20$ years, and $5.91 \%$ were 21 years and above.

\subsection{Measurements}

Work intensification: the scale developed by Wang Juanjuan and Zhao Huijun is suitable for Chinese situation [24]. We assessed work intensification with 10 items measuring two dimensions (work intensity and work time). Work intensity was assessed with 7 items including "it's more and more difficult to have a little rest during work". Work time was assessed with 3 items including "it is more and more common to handle work affairs at home at night (telephone, Wechat, email, etc.)"(1="never", 5="often").

Employee learning: we measured employee learning with 8 items [25]. An example is "I am trying to expand my knowledge and skills"(1="never", 5="often").

Cognitive appraisal: cognitive appraisal was assessed with8 items including two dimensions(challenge appraisal and hindrance appraisal) [26]. Challenge appraisal was measured with 4 items including "this will help me learn a lot". Hindrance appraisal was assessed with 4 items including "this will hinder me from achieving anything"(1="never", $5=$ "often").

Control variables: according to previous studies, the variables that may affect job intensification, employee learning in the workplace, and cognitive appraisal are taken as control variables, including gender, age, education background and working years.

\section{RESULTS}

\subsection{Reliability Testing}

The reliability of the measurement model is mainly measured by the Cronbach's Alpha and the combined reliability (CR) calculated by the PLS Algorithm. The results are shown in Table 1. Cronbach's Alpha is above 0.7 , and the minimum is 0.892 . Combined reliability value is above 0.7 , and the minimum is 0.925 , which shows that the measurement model has good reliability.

\subsection{Validity Testing}

The validity testing is mainly conducted from two aspects: convergent validity and discriminant validity. Convergent validity is measured by the outer loading and average extraction variance (AVE) calculated by PLS Algorithm. The results are shown in Table 1. The results show that outer loading of work intensification is between 0.758 and 0.871 , outer loading of employee learning is between 0.686 and 0.892 , and challenge appraisal is between 0.840 and 0.911 , and outer loading of hindrance appraisal is between 0.830 and 0.897 . In a word, the outer loadings of each variable basically exceed 0.7. At the same time, the AVE all exceed 0.5, and the minimum is 0.644 .

The discriminant validity is mainly measured by the correlation coefficient between variables calculated by PLS Algorithm. The results are shown in Table 1. Since the square root of the AVE of each variable is greater than the absolute value of the correlation coefficient between the variables, the possibility of collinearity 
between the variables is very low. To sum up, the measurement model has good validity and reliability.

\subsection{Model Hypothesis Verification}

In this study, the relationship between the variables in the structural model was tested through the PLS Algorithm and Bootstrapping (5000 times) of SmartPLS3.2. The results are shown in Table 2. It can be seen from the table that work intensification has a significant positive impact on employee learning $(\beta=0.24, p<0.001)$, challenge appraisal $(\beta=0.21, p<0.01)$ and hindrance appraisal $(\beta=0.213, p<0.01)$. At the same time, challenge appraisal has a significant positive effect on employee learning $(\beta=0.311, p<0.001)$, so the mediating effect of challenge appraisal between work intensification and employee learning can be further explored. Besides, although hindrance appraisal has a negative effect on employee learning ( $\beta=-0.015$, NS), this effect is not significant and does not meet the basic conditions of mediation, so the hypothesis $\mathrm{H} 2$ is rejected.

This study mainly refer to the method proposed by Nitzl [27] When testing the mediating role of challenge appraisal. The results are shown in Table 3. First, the indirect effect value of challenge appraisal between work intensification and employee learning is 0.064 , $\mathrm{p}<0.05$, and the $95 \%$ confidence interval does not include 0 . Therefore, the mediating effect of challenge appraisal is significant, and hypothesis H1 is supported. Secondly, the effect of work intensification on employee learning became insignificant $(\beta=0.047$, NS) when the variable of challenge appraisal was introduced, and the impact of challenge appraisal on employee learning was still significant $(\beta=0.304, \mathrm{P}<$ 0.001). Therefore, challenge appraisal completely mediated the relationship between work intensification and employee learning.

\section{DISCUSSION}

\subsection{Conclusion}

The main conclusions of this research are as follows. First, the phenomenon of work intensification and employee learning are widespread in the workplace. For the appraisal of work intensification, challenge appraisal and hindrance appraisal all exist. Specifically, the negative impact of work intensification is considered by some employees to be overcome, and they can use existing resources to achieve development. At the same time, work intensification also can be regarded as a hindrance by some employees, which may cause resource depletion. Second, work intensification has a significant positive impact on employee learning, and this impact is mainly due to the complete mediating effect of challenge appraisal. That is to say, work intensification can promote employee learning by enhancing employee challenge appraisal.

\subsection{Research Significance}

The theoretical significance of this research are as follows. First, this study enriches and develops the existing work intensification research. Although a large number of studies abroad have explored the antecedents and aftereffects of work intensification, the research on work intensification in China is still relatively lagging. Besides, previous studies have explored the impact of work intensification on employees' personal factors (physical and mental health, emotional exhaustion, etc.), but most of them focus on the negative aspects. Few studies have explored the potential value of work intensification, especially the potential value of work intensification on employee learning. Secondly, based on the cognitive interaction theory of stress, this paper interprets the relationship between work intensification and employee learning from the perspective of cognitive appraisal, and reveals the important mediating role of challenge appraisal. The research shows that work intensification can be regarded as a challenge, thus promoting the learning behaviour of employees. This result verifies that cognitive appraisal plays an important mediating role between work demand and individual factors.

This study also provides some enlightenment for management practice. First, work intensification is not "worthless", but also has positive effects on employees. Organizations can appropriately increase work intensity and work demand to help employees improve their skills and promote employee learning. It is worth noting that work intensification promotes employee learning through the mediating role of challenge appraisal. Therefore, organizations should pay attention to the degree of work intensification and its possible negative impact on employee. Secondly, more attention should be paid to the cognitive appraisal of employees on work intensification when recruiting, training and promoting, and the challenge appraisal of employees should be cultivated from various aspects. Besides, the research shows that only when employees regard work intensification as a challenge, can employee learning be promoted. Therefore, organizations should try their best to select the person with the tendency of challenge appraisal. In terms of daily training and organizational culture publicity, the organization should actively guide the employees to positively evaluate the work intensification, so as to establish a competitive learning organization. 
Table 1. Short cut keys for the template

\begin{tabular}{|c|c|c|c|c|c|c|c|}
\hline Variables & $\begin{array}{c}\text { Cronbach's } \\
\text { Alpha }\end{array}$ & CR & AVE & $\begin{array}{c}\text { Employee } \\
\text { learning }\end{array}$ & $\begin{array}{c}\text { Work } \\
\text { intensification }\end{array}$ & $\begin{array}{c}\text { Challenge } \\
\text { appraisal }\end{array}$ & $\begin{array}{c}\text { Hindrance } \\
\text { appraisal }\end{array}$ \\
\hline Employee learning & 0.923 & 0.935 & 0.645 & 0.803 & & & \\
\hline Work intensification & 0.939 & 0.948 & 0.644 & 0.106 & 0.803 & & \\
\hline Challenge appraisal & 0.892 & 0.925 & 0.755 & 0.299 & 0.202 & 0.869 & \\
\hline Hindrance appraisal & 0.898 & 0.928 & 0.764 & 0.202 & 0.228 & 0.226 & 0.874 \\
\hline
\end{tabular}

Note: The shaded value is the square root of AVE

Table 2. Results of model hypothesis verification

\begin{tabular}{|l|l|l|l|l|}
\hline The paths of variables & $\beta$ & $\mathrm{M}$ & STDEV & $|\mathrm{O} / \mathrm{STDEV}|$ \\
\hline Work intensification -> Employee learning & $0.240^{\star \star \star}$ & 0.266 & 0.058 & 4.125 \\
\hline Work intensification -> Challenge appraisal & $0.210^{\star \star}$ & 0.225 & 0.065 & 3.214 \\
\hline Work intensification -> Hindrance appraisal & $0.213^{\star \star}$ & 0.232 & 0.067 & 3.187 \\
\hline Challenge appraisal -> Employee learning & $0.311^{\star \star *}$ & 0.333 & 0.074 & 4.197 \\
\hline Hindrance appraisal -> Employee learning & -0.015 & -0.026 & 0.103 & 0.143 \\
\hline
\end{tabular}

Note:** means $p<0.01$, ${ }^{* * *}$ means $p<0.001$

Table 3. The mediating role of challenge appraisal

\begin{tabular}{|c|c|c|c|c|c|}
\hline The paths of variables & $\begin{array}{c}\text { Indirect } \\
\text { effect value }\end{array}$ & $M$ & STDEV & |O/STDEV| & $\begin{array}{c}\text { Confidence } \\
\text { interval (95\%) }\end{array}$ \\
\hline $\begin{array}{c}\text { Work intensification -> Challenge } \\
\text { appraisal -> Employee learning }\end{array}$ & $0.064^{*}$ & 0.073 & 0.030 & 2.113 & {$[0.030,0.127]$} \\
\hline $\begin{array}{c}\text { Work intensification -> Employee } \\
\text { learning }\end{array}$ & 0.047 & 0.052 & 0.075 & 0.625 & \\
\hline $\begin{array}{c}\text { Challenge appraisal -> Employee } \\
\text { learning }\end{array}$ & $0.304^{\star * *}$ & 0.324 & 0.078 & 3.897 & \\
\hline
\end{tabular}

Note: ${ }^{*}$ means $p<0.05,{ }^{* \star \star}$ means $p<0.001$

\subsection{Future Research and Limitations}

We still need further study in the future due to the limitations of personal ability and research conditions. First, the breadth of research samples needs to be strengthened. The future research should increase the samples of different industries and enterprises to improve the external validity of the research conclusions. At the same time, we can try to do the differentiation research according to gender, working years and education background, so as to further explore the influence mechanism of work intensification on employee learning. For example, compared with senior employees, does work intensification have a more significant positive effect on the challenge appraisal and learning behaviour of new employees?
Secondly, this study only examined the linear relationship between work intensification and employee learning. Work intensification can promote learning behaviour through challenge appraisal, but work intensification will inevitably have a very adverse impact on employees' health and emotions [22, 28]with the increase of work intensification degree and time accumulation, which is very likely to have a negative impact on employee learning. Therefore, there may be a non-linear relationship between work intensification and employee learning (e.g. inverse U-shaped). Future research can deeply analyse the impact of work intensification on employees' attitude and behaviours.

\section{REFERENCES}

[1] White, M.R., et al., 'High-Performance' Management Practices, Working Hours and Work- 
Life Balance. Social Science Electronic Publishing, 2003.

[2] Paškvan, M. and B. Kubicek, The Intensification of Work. 2017: Springer International Publishing.

[3] Green, F., Work Intensification, Discretion, and the Decline in Well-Being at Work. Eastern Economic Journal, 2004. 30(4): p. 615-625.

[4] Juanjuan Wang., et al., Concept, Structure, Measurements and Integrated Research Framework of Work Intensification. Human Resources Development of China, 2019. 36(09): p. 32-47.

[5] Franke, F., Is Work Intensification Extra Stress? Journal of Personnel Psychology, 2015. 14(1): p. 17-27.

[6] Jianzhong Shi, The Theory and Practice of Overwork: The Foreign Experience, Present Situation of China and Research Prospect. Population \& Economics, 2019(02): p. 105-118.

[7] Birdi, K., C. Allan, and P. Warr, Correlates and perceived outcomes of 4 types of employee development activity. Journal of Applied Psychology, 1997. 82(6): p. 845-857.

[8] Min Tang, Research on the New Employees' Workplace Learning and its Influencing Factors. 2015, East China Normal University.

[9] Yanchun Zou., et al., On the Same Page: The Effect of Leader-Subordinate Psychological Capital Congruence on Subordinates' Learning Behavior. Human Resources Development of China, 2019. 36(07): p. 24-36.

[10] Guoquan Chen., et al., Impact mechanism of leader empowering behaviour on individual learning capability. Science Research Management, 2017. 38(03): p. 114-127.

[11] Naveh, E., T. Katz-Navon, and Z. Stern, Active learning climate and employee errors: The moderating effects of personality traits. Journal of Organizational Behavior, 2015. 36(3): p. 441-459.

[12] Bezuijen, X.M., et al., Pygmalion and Employee Learning: The Role of Leader Behaviors. Journal of Management Official Journal of the Southern Management Association, 2009. 35(5): p. 12481267.

[13] Meurs, J.A. and P.L. Perrewe, Cognitive Activation Theory of Stress: An Integrative Theoretical Approach to Work Stress. Journal of Management, 2011(4).

[14] Kai Gan and Xin Zhao, A Longitudinal Study of Reciprocal Relationship between Work Stress and Employee Learning among R\&D Personnel.
Science \& Technology Progress and Policy, 2013. 30(19): p. 148-152.

[15] Lazarus, R.S. and S. Folkman, Transactional Theory and Research on Emotions and Coping. European Journal of Personality, 1987. 1(3): p. $141-169$.

[16] Lazarus, R.S. and S. Folkman, Stress, Appraisal, and Coping. 1984.

[17] Webster, J.R., T.A. Beehr, and K. Love, Extending the challenge-hindrance model of occupational stress: The role of appraisal. 2011. 79(2): p. 505516.

[18] Xu Zhang., et al., The Relationship between Rewards and Creativity Performance in a Cognitive Appraisal Perspective: Moods and Cognitive Recourse as Moderators. Nankai Business Review, 2017. 20(05): p. 144-154.

[19] Ogbonnaya, C., et al., Integrated and Isolated Impact of High-Performance Work Practices on Employee Health and Well-Being: A Comparative Study. Journal of Occupational Health Psychology, 2016.

[20] Wood, S., et al., Enriched job design, high involvement management and organizational performance: The mediating roles of job satisfaction and well-being. 2012. 65(4): p. 419445.

[21] Neirotti, P., Work intensification and employee involvement in lean production: new light on a classic dilemma. International Journal of Human Resource Management, 2018(1): p. 1-26.

[22] Paškvan, M., et al., Cognitive appraisal of work intensification. 2016. 23(2): p. 124-146.

[23] Xin Zhao., et al., A Review of Researches on Entrepreneurial Performance. Foreign Economics \& Management. 2013. 35(02): p. 52-62.

[24] Huijun Zhao and Juanjuan Wang, Research on the Structure Exploration and Scale Development of Work Intensification in Chinese Context. Business Management Journal, 2019. 41(05): p. 192-208.

[25] Bezuijen, X.M., et al., How leaders stimulate employee learning: A leader-member exchange approach. Journal of Occupational \& Organizational Psychology, 2010. 83(3).

[26] Searle, B.J. and J.C. Auton, The Merits of Measuring Challenge and Hindrance Appraisals. Anxiety Stress \& Coping, 2014. 28(2): p. 1-41.

[27] Nitzl, C., J.L. Roldàn, and G.C. Carrión, Mediation Analysis in Partial Least Squares Path Modeling: Helping Researchers Discuss More Sophisticated 
Models. Industrial Management \& Data Systems, 2016. 116(9): p. 1849-1864.

[28] Krause, N., T. Scherzer, and R. Rugulies, Physical workload, work intensification, and prevalence of pain in low wage workers: Results from a participatory research project with hotel room cleaners in Las Vegas. American journal of industrial medicine, 2005. 48: p. 326-37. 